\title{
Una aproximación a los cambios religiosos en Chile, 1968-2008
}

\author{
Reinaldo Tan Becerra ${ }^{1}$
}

\begin{abstract}
Resumen
El artículo muestra, a través de un recorrido histórico-sociológico, los grandes cambios religiosos que han sucedido en Chile en los últimos cuarenta años. La reflexión es apoyada por datos estadísticos y hechos históricos que apoyan la tesis de cambio en la conformación del campo religioso en Chile.
\end{abstract}

Palabras clave: Religión, Historia de Chile, Pluralismo religioso.

\begin{abstract}
The paper shows, through a historical-sociological, the great religious changes that have occurred in Chile in the last forty years. Reflection is supported by statistics and historical facts to support the thesis of change in shaping the religious field in Chile.
\end{abstract}

Key words: Religion, History of Chile, Religious pluralism.

1 Sociólogo, Magíster @ en Estudios sociales y políticos latinoamericanos. Investigador en CISOC-Bellarmino. 
Los chilenos han vivido en los últimos 40 años, un período caracterizado por profundos cambios en su sociedad. Desde los 60, época de "la efervescencia social, la transgresión a las costumbres, el desenfreno eufórico por el cambio y un fuerte optimismo y confianza en el futuro, fueron los signos que marcaron la pauta... la década se convirtió en una verdadera bisagra histórica". ${ }^{2}$ En esta década se realiza el Concilio Vaticano II, giro de la Iglesia Católica Romana hacia una apertura al mundo, todo un proceso de renovación que tuvo su canal a nivel latinoamericano a través de la Segunda Conferencia Episcopal Latinoamericana en Medellín (1968). Pasando por el 11 de septiembre de 1973, “...terremoto que azotó vidas, concepciones de comunidad y conciencias" ${ }^{\prime \prime}$, acompañado del proyecto refundacional de país del Régimen Militar de Pinochet de "restaurar la chilenidad, la justicia y la institucionalidad quebradas" ${ }^{\prime \prime}$, a través de un cambio en la conciencia colectiva del país a partir del ejercicio de la fuerza y de los hechos... (Con una fuerte) impronta economicista con que se revestiría su misión de reconstrucción nacional" ${ }^{\prime \prime}$. De lo que prevalece hasta el presente el predominio de una economía de tipo neoliberal. Lo cual abrió el camino al cambio de conciencia buscado por el Régimen de Pinochet, una libertad cuyo eje es el mercado, el cual habría de revolucionar silenciosamente a la sociedad chilena. ${ }^{6} \mathrm{Ya}$ en los 90 se asiste al retorno del sistema democrático, abriendo el horizonte de libertades civiles que se encontraba vedado en el Régimen de Pinochet. Se inaugura un período de profundización de libertades políticas, acompañadas por las ya desarrolladas libertades económicas abiertas en el Régimen. Finalmente, el 2000 llega acompañado de la globalización, posibilitado por el acceso a tecnologías de comunicación (de las cuales la más destacada es internet) que permiten a grupos numerosos de la población

\footnotetext{
2 Correa, S. y Otros. (2001). Historia del siglo XX chileno. Santiago: Editorial Sudamericana, p. 226

3 Op. Cit. p. 283.

4 Op. Cit. p. 284.

5 Op. Cit. p. 287

6 Op. Cit. p. 294.
} 
acceder a mundos diversos tanto dentro como fuera del territorio nacional.

La tradicional sociedad chilena, caracterizada por una fuerte presión social que anulaba todo comportamiento disonante con aquellos legitimados por la cultura predominante, ha dejado de existir. ${ }^{7}$ Nos encontramos hoy con el predominio de la autonomía personal por sobre la comunidad, pérdida de autoridad de las tradiciones y el aumento de alternativas en los modos de vida, los cuales han conllevado a un proceso de individuación en la forma de construcción del proyecto personal de vida: uno define por sí mismo las elecciones, valores y relaciones que van armando su proyecto de vida. ${ }^{8}$ Somos testigos de la instalación del pluralismo y con él la emergencia de diversos sistemas de valores y cosmovisiones. ${ }^{9}$

Esto nos lleva a un inevitable cambio en la cosmovisión de los chilenos en estos 40 años, su forma de ver e interpretar el mundo ha cambiado.

Los chilenos, hombres y mujeres, se ven hoy frente al desafío de responder a sus propias vidas con una conjugación de los retazos heredados de su tradición, que constituye(ía) un nosotros -que da(ba) pertenencia y unidad- y de las inéditas potencialidades provenientes de la autonomía personal de la que son portadores hoy.

En este marco, cobra mayor fuerza y necesidad, tanto para hombres y mujeres, "la expectativa de un mensaje sistemático capaz de dar un sentido unitario a la vida, proponiendo a sus destinatarios privilegiados una visión coherente del mundo y de una existencia humana, y dándole los medios de realizar la inte-

7 Poblete S.J., R. (1967, noviembre). Santiago ¿Provincia Católica? Mensaje (Número especial), 164, 529.

8 Programa de Naciones Unidas para el Desarrollo, PNUD (2002). Desarrollo Humano en Chile 2002 [Versión electrónica]. Santiago de Chile, p. 189.

9 Berger, P. \& Luckman, T. (1996, invierno). Modernidad, pluralismo y crisis de sentido [Versión electrónica]. Estudios Públicos, 63, 19. 
gración sistemática de su conducta cotidiana, así pues, capaz de proporcionarles justificaciones de existir como existen: es decir, en una posición social determinada" ${ }^{10}$ Es decir, dar respuesta al interés religioso.

La potencia de autonomía, radicada en el pluralismo y la individualidad, abre las puertas a diversas formas de ver e interpretar el mundo, las cuales concuerdan en menor o mayor grado con las formas religiosas institucionalizadas de cosmovisión existentes en la sociedad chilena. Cosmovisiones que se encuentran en particular dinamismo desde los 60 para la sociedad chilena, situación que se verifica en cuanto religiosidad en el siguiente cuadro:

\section{Cuadro 1: Religión en Chile. Censos de 1985-2002}

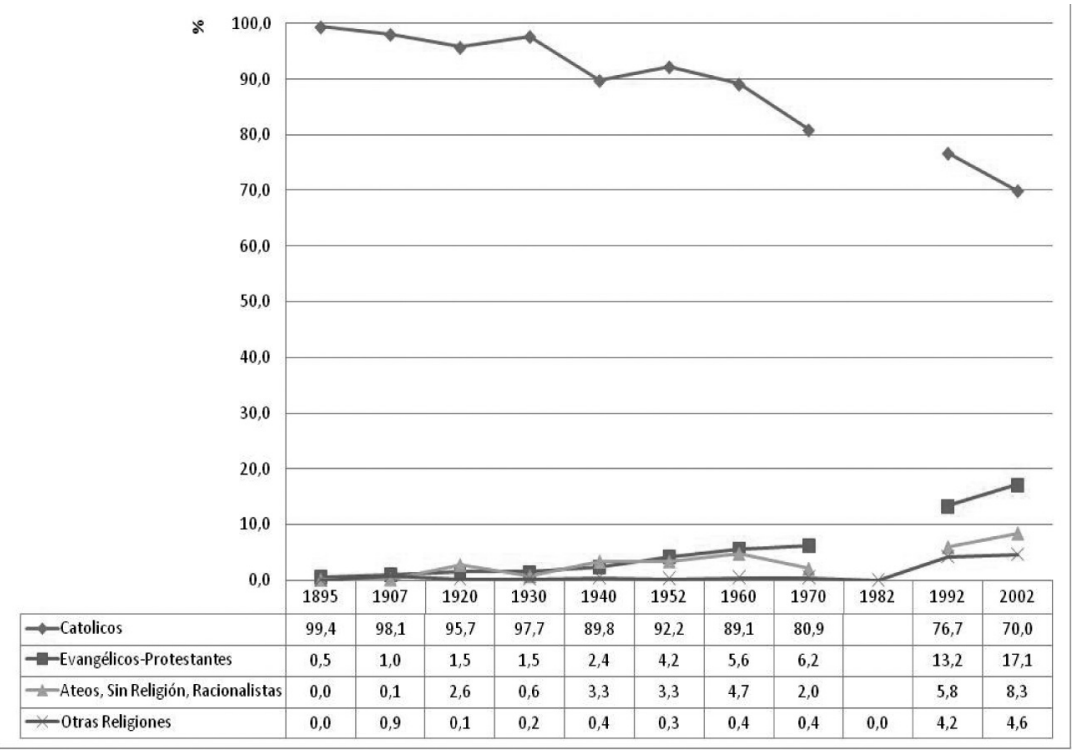

Fuente: Elaboración propia a partir del texto de Juan Guillermo Prado "La Estampida de los Fieles" (2008)

10 Bourdieu, P. 1971; citado por Suárez, J. (2006). Pierre Bourdieu y la Religión: una introducción necesaria. 
Es en la década de los 60 donde la Iglesia Católica experimenta su caída más fuerte, entre censos, en el siglo XX, con un descenso cercano al $9 \%$ de sus fieles, encontrándose con una baja permanente de fieles desde ese entonces. Distinto es el caso de Evangélicos-Protestantes y otras religiones, quienes muestran, para el mismo período, significativos crecimientos, en particular estos últimos: pasan de un 0,4\% en 1970 a un 4,2\% en 1992.

La religiosidad de los chilenos ya no es mediada, exclusivamente, "ni por una esfera especializada de instituciones religiosas ni por otras instituciones públicas primarias. Este acceso directo al espacio sagrado -más exactamente, a una variedad de temas religiosos- es el que hace que la religión sea un fenómeno de la "esfera privada". ${ }^{11}$ Estamos hoy frente a formas de religión que difieren "de un modo significativo de las formas anteriores y más antiguas de religión que se caracterizaban o bien por la difusión del cosmos sagrado a través de la estructura institucional de la sociedad o a través de la especialización institucional de la religión". ${ }^{12}$ Desde los individuos, desde sus espacios privados, se redefinen los vínculos que tienen con la religión y su experiencia religiosa.

En este período se han abierto las puertas para el pluralismo en su versión religiosa, y sus implicancias tanto a nivel de la institucionalidad religiosa como en las conciencias subjetivas de los individuos. En términos institucionales, supone el establecimiento de un "mercado religioso", en el sentido de que "las instituciones religiosas deben competir por la adhesión de su supuesta clientela. Esta competencia se vuelve naturalmente más intensa bajo un régimen de libertad religiosa"13, marco jurídico imperante hoy en Chile (Ley 19.638) ${ }^{14}$.

11 Luckmann, T. (1973). La religión invisible: el problema de la religión en la sociedad moderna. Salamanca, España: Ediciones Sígueme, p. 114.

12 Ídem.

13 Berger, P. (2005). Pluralismo Global y Religión [Versión electrónica]. Estudios Públicos, $98,10$.

14 Establece normas sobre la constitución jurídica de Iglesias y Organizaciones Religiosas. 
A nivel individual Peter Berger sintetiza el impacto en una frase: "la religión pierde su condición de realidad que se da por sentada en la conciencia". ${ }^{15}$ Es decir, la religión era parte esencial de lo que se daba por sentado en una sociedad, hoy el pluralismo debilita esta homogeneidad, ${ }^{16}$ el individuo ahora debe "reflexionar acerca de los supuestos cognitivos y normativos de su tradición, y en consecuencia tiene que escoger ${ }^{\prime \prime 17}$. Es una religión que pierde su carácter prescrito, determinado para el individuo, pasando a adquirir un claro componente voluntario. Un católico moderno "puede profesar las mismas doctrinas y entregarse a las mismas prácticas que sus antepasados de una aldea católica tradicional. Pero él ha decidido -y debe continuar decidiendo- creer y conducirse así. Ello transforma su religión en algo más personal y más vulnerable. Dicho de otro modo, la religión se subjetiviza y la certeza religiosa resulta más difícil de alcanzar" ${ }^{18}$ Pero esto no conlleva una pérdida en la creencia en la existencia de Dios pero sí un replanteamiento al cómo es la conexión con Dios.

¿Qué cambios han ocurrido en el campo religioso? ¿Qué ha ocurrido con el habitus religioso de los chilenos? ¿Qué actores se han incorporado en la pugna por el campo religioso?

Claves aquí son los conceptos de campo y de habitus de la teoría social de Bourdieu. Campo, es "un campo de fuerzas que asegura la reproducción del poder, como un campo de luchas dentro del cual los agentes se enfrentan para conservar o transformar la estructura. El campo es tanto reproducción como cambio."19 Por otro lado, "el habitus es el cuerpo y la mente humana socializada. Las estructuras objetivas no existen fuera de la conciencia y la voluntad de los agentes, y orientan sus prácticas y sus representaciones de acuerdo con las reglas del juego. El ha-

15 Berger, 2005, p. 10.

16 Ídem.

17 Ídem.

18 Op. Cit. p. 11.

19 De la Torre, R. (2002). El campo religioso, una herramienta de duda radical para combatir la creencia radical. Obtenido de http:/ / www.cge.udg.mx/revistaudg/rug24/bourdieu5. html 
bitus funciona también subjetivizando, es decir, interiorizando la sociedad, según la posición particular del sujeto y su trayectoria autobiográfica." ${ }^{20}$.

Estos nos permiten adentrarnos en el significado de los campos religiosos, y dentro de ellos el sentido de sus agentes, institucionales y no institucionales; y en el habitus religioso de los chilenos: sus prácticas, creencias, formas de transmisión de la fe.

Clave es la distinción que hace Bourdieu dentro del campo religioso, al identificar que este se encuentra conformado por dos agentes: "un cuerpo de especialistas religiosos, socialmente reconocidos como los detentadores exclusivos de la competencia específica que es necesaria para la producción o la reproducción de un cuerpo deliberadamente organizado de saberes secretos..., la constitución de un campo religioso es correlativa de la desposesión objetiva de los que están excluidos de él y que se encuentran constituidos por eso mismo en tanto que laicos (o profanos en el doble sentido del término) desposeídos del capital religioso (como trabajo simbólico acumulado) y que reconocen la legitimidad de esta desposesión por el solo hecho de que la desconocen como tal." ${ }^{\prime 21}$

Esto nos configura un marco conceptual que nos permite entrar en diálogo con el período que es de interés de estudio, 19682008.

El cristianismo ha sido de gran relevancia histórica en la sociedad chilena, en particular el catolicismo, socializando su forma de comprender y ver el mundo, su relación con Dios, configurando una cosmovisión que ha sido parte de la gran mayoría de los chilenos, instalando un habitus que reproduce un determinado campo religioso. ¿Qué ha ocurrido con la Iglesia Católica y su ubicación dentro del campo religioso chileno? ¿Están satisfechos

20 Ídem.

21 Bourdieu, P. (1971). Génesis y estructura del campo religioso [Versión electrónica]. pp. 42 y 43. 
los laicos con la mediación de los cuerpos de especialistas religiosos de sus religiones institucionales? Será esta insatisfacción de no responder a un nuevo campo religioso, donde se encuentran más actores mediadores, la causa del fuerte descenso experimentado por la Iglesia Católica en los últimos 40 años?

Pero esto ¿es así? ¿O estamos frente a un cambio que sólo es expresión de la "dermis" del campo religioso, manifestando una aparente pluralización que no es expresión del habitus? Persistiendo, esencialmente este, pero ¿con otro "envase"?

No hay duda de que hay cambios en lo religioso, la pregunta es en qué nivel y profundidad, que lleve a un cambio del habitus religioso en una sociedad chilena.

Esto presenta un claro desafío para la teología, dar cuenta de un campo religioso en cambio, en una sociedad crecientemente plural y en un marco institucional religioso del cual es parte, que la posibilita e imposibilita en sus oportunidades de respuesta. Pero para acceder a los "datos" de esta realidad plural requiere de la colaboración de las ciencias sociales, y en particular de una sociología que sea capaz de constatar los cambios en el campo y habitus religioso. Bourdieu ofrece una puerta de respuesta para vencer la particular profundización de la "precariedad reflexiva de las realidades sociales"22 de la que adolece la teología.

Responder al desafío que significa este nuevo escenario religioso es de importancia tanto para la sociología como para la teología, pero es para esta última donde se juega "la razonabilidad y credibilidad de la fe $\mathrm{fe}^{\prime 23}$, y la necesidad de identificar el impacto que ella tiene sobre el actual campo religioso.

22 Miranda, P. (2006). Doctrina Social de la Iglesia y Ciencias Sociales. ANALES, Facultad de Teología, Pontificia Universidad Católica de Chile, Volumen LVII. p. 120.

23 Op. Cit. p. 122 


\section{Bibliografía}

Berger, P. \& Luckman, T. (1996, invierno). Modernidad, pluralismo y crisis de sentido [Versión electrónica]. Estudios Públicos, 63, 19.

(2005). Pluralismo Global y Religión [Versión electrónica]. Estudios Públicos, 98, 10.

Bourdieu, P. (1971). Génesis y estructura del campo religioso [Versión electrónica].

Correa, S. y Otros (2001). Historia del siglo XX chileno. Santiago: Editorial Sudamericana.

De la Torre, R. (2002). El campo religioso, una herramienta de duda radical para combatir la creencia radical. Obtenido de http://www.cge.udg. $\mathrm{mx} /$ revistaudg/rug24/bourdieu5.html

Luckmann, T. (1973). La religión invisible: el problema de la religión en la sociedad moderna. Salamanca, España: Ediciones Sígueme.

Poblete S.J., R. (1967, noviembre). Santiago ¿Provincia Católica? Mensaje (Número especial), 164, 529.

Programa de Naciones Unidas para el Desarrollo, PNUD (2002). Desarrollo Humano en Chile 2002 [Versión electrónica]. Santiago de Chile. 